\title{
Numerical Study of the Hydrodynamic Pressure Field Generated due to Ship Motion at Different Speeds
}

\author{
A. Nasseroleslami ${ }^{1 \dagger}$, A. Sarreshtehdari ${ }^{1}$ and M. Salari ${ }^{2}$ \\ ${ }^{1}$ Faculty of Mechanical Engineering, Shahrood University of Technology, Shahrood, Semnan, Iran \\ ${ }^{2}$ Department of Mechanical Engineering, Imam Hussein University, Tehran, 1698715461, Iran \\ $\dagger$ Corresponding Author Email: Amir.eslami@ live.com
}

(Received December 23, 2019; accepted February 29, 2020)

\begin{abstract}
Ship movement in the shallow seas creates a significant hydrodynamic pressure field about the ship that has effect on the environmental structures such as waterway beds, stationary or moving neighbored vessels, and can also affect marine life. Therefore, the study of this phenomenon is very important in many applications. The present study investigated the hydrodynamic pressure field caused by an oil tanker with $247 \mathrm{~m}$ long, 53 $\mathrm{m}$ wide and $17 \mathrm{~m}$ draft moving at different speeds of 10,15 and 20 knots on a sea level with a depth of $80 \mathrm{~m}$. The fluid flow governing equations including the continuity equation, the momentum equations, and the K- $\varepsilon$ turbulence model are solved numerically and the SIMPLE algorithm is used to correlate the pressure and velocity fields. An accurate Trimmer's structured mesh has been utilized to discrete the studied domain around the ship. To validate the methodology, the obtained dimensionless velocity field is compared with those presented by other works a good consistency is observed. As expected, the magnitude of the hydrodynamic pressure field varied as a function of the distance to the body of the vessel, ship's traveling velocity and magnitude of the draft. In this study, the minimum effects of the pressure were for the case of 10 knots (the minimum working velocity of heavy vessels) and $80 \mathrm{~m}$ of depth with a maximum pressure of 980 $\mathrm{Pa}$. The results show that the pressure field dissipation occurs more rapidly in close distances to the vessel, and the pressure field domain decreases with a lower slope in far away from of the body. a hydrodynamic pressure correlation is obtained based on the depth and ship's velocity. Two and three-dimensional hydrodynamic pressure contours are also presented for different depths and velocities. Moreover, he hydrodynamic pressure increments in 12 and $7 \mathrm{~m}$ drafts are investigated and that shows after the 3/4 height of the bulbous bow lies below the sea surface, the increase in draft has little effect on the hydrodynamic pressure field.
\end{abstract}

Keywords: Hydrodynamic pressure field; Draft; Oil tanker; CFD.

\section{NOMENCLATURE}

$g \quad$ acceleration due to gravity

$\dot{m}_{p q} \quad$ mass transfer from phase $\mathrm{q}$ to phase $\mathrm{p}$

$P_{H} \quad$ hydrodynamic Pressure

$F_{r} \quad$ Froude number

$S_{\alpha_{q}}$ source

$u \quad$ velocity

$\mathrm{V} \quad$ cell volume

\section{INTRODUCTION}

Today, more than about two-third of the world's transportation is carried through the sea and more ships are traveling in the restricted waterways. The ship motions changes the pressure field around them called as the ship's hydrodynamic

$\begin{array}{ll}\alpha & \text { volume fraction } \\ \rho & \text { density } \\ \mu & \text { viscosity } \\ \tau & \text { shear stress }\end{array}$

Subscript and Superscript

$n+1$ the time step number being calculated $\mathrm{q}, \mathrm{p}$ fluid phase

pressure field (SHPF). In shallow waters, this SHPF may affect the seabed and shores and cause relevant environmental erosion. The interaction between this field and the body of the ship may also cause problems for the dynamic instability of other neighbor ships. However, the pressure field of each ship is unique characteristics for the ship 
and differs from the other vessels (Deng et al. 2017). This pressure field is also used in military applications to identify the vessels. Since 1960, researchers have focused on safe navigation. Bishop and Donelan (1987) showed that the pressure drop and pressure sensor distance from the vessel floor were the most important determinants of the pressure fiseld. Tuck (1978) investigated the hydrodynamic pressure field created by a relatively narrow vessel traveling at low velocities in shallow waters.

Some experimental works on the towing tank and sea are reviewed in reference regarding the effects of ship type and flow velocity (Deng et al. 2017). There have been a number of theoretical and analytical models proposed to solve this problem (Sahin and Hyman, 2001). One of which is Zhang's analytical model, evaluated regardless of the nonlinear effects in open waters (Zhang and $\mathrm{Gu}, 2006$ ). Gourlay (2000) attempted to predict the hydrodynamic force of a ship using CFD. Deng et al. (2014) also characterized the hydrodynamic pressure fields over a wide range of Froude numbers in the rectangular channels. Deng et al. (2017) studied the effect of the hydrodynamic pressure field on the stepped channels. regarding the effect of floor and walls in the limited waters. McArthur (2011) obtained an initial understanding of the hydrodynamic systems by the ship, which was the three pressure zones under the ship. These pressure zones were fixed to the body of the ship. This theory can be useful in limited cases; therefore, to rely on it is to ignore the distant effects of the ship; Although this theory was understandable thanks to Dand (1977), it cannot explain all of the hydrodynamics produced, especially over long distances under the ship, and researchers have paid less attention to this issue. Dand (1977) described the effects of interactions between ships that move very close together or move near the shore or submarine tanks. Today, these principles are the foundation of the hydrodynamic theories of the ships. Pressure waves of a high-velocity vessel can jeopardize the safety of other vessels or buildings or cause seabed wash away (Zhang and Gu, 2006). Lazauskas (2007) performed numerical calculations and analyses to predict the underlying pressure properties of a 5900-tonne displacement air warfare destroyer and found that the pressure changes may affect the seabed. Moreover, considering the dispersion nonlinearities and the unstable effects, Bozinsky's complex equations for the calculation of ship hydrodynamics are solved by Chen and Sharma (1995) in a rectangular cannel for near-critical velocities. Meng et al. (2018) have investigated the hydrodynamics of the vessel in shallow waters with uneven depths. Meng also focused on theoretical solutions and presented the mathematical models for the hydrodynamic pressure field created by the ship.
Ship movement in the shallow sea creates a significant hydrodynamic pressure field that can affect the ship-to-ship interaction during overtaking operations and marine life in shallow water. The purpose of this study was to investigate how to reduce the hydrodynamic pressure below a commercial vessel up to half the length of the vessel and near the seabed. The movement of the ship causes the water to move at different depths. This movement of the vessel causes hydrodynamic pressure at different depths.

This study aims to investigate this pressure field numerically for a $247 \mathrm{~m}$ long, $53 \mathrm{~m}$ wide at depth of $80 \mathrm{~m}$ and $17 \mathrm{~m}$ draft. The ship has speed of 10, 15 and 20 knots. The solution domain mesh is Trimmer and the K- $\varepsilon$ and VOF (Volume of Fluid) turbulence models and Implicit Unsteady mode are used for this solution.

\section{The GOVERNING EQUATIONS}

Numerical analyses have been modeled as two phases due to the presence of two phases of climate. The effects of the free surface have been analyzed. The lighter phase or the air is higher than the heavier phase or the water. In this study, the VOF model, which is a subset of the Euler-Euler model and a surface tracking method, is applied to a fixed Eulerian mesh. The formulation of this model is based on the assumption that the fluids do not mix. For each phase, a scalar variable is defined as the volume fraction of the fluid. In the studied control volume, the sum of the volume fractions of all phases is equal to one.

One of the VOF model subsets is the Open Channel model defined in the Fluent software. In these currents, the wave propagation and free surface behavior are more important. The dominant forces in the free surface modeling are the gravity and inertia forces. This feature is mainly suitable for the offshore applications.

\subsection{Volume Fraction Equation}

It is possible to follow a common multi-phase plane by solving a continuum equation for the volume fraction of water and air phases. For each phase q:

$$
\begin{aligned}
\frac{1}{\rho_{q}} *\left[\frac{\partial}{\partial t}\left(\alpha_{q} \rho_{q}\right)+\nabla\right. & \cdot\left(\alpha_{q} \rho_{q} \overrightarrow{v_{q}}\right) \\
& =S_{\alpha_{q}}+\sum_{p=1}^{n}\left(\dot{m}_{p q}-\dot{m}_{q p},\right.
\end{aligned}
$$

Where, $\dot{m}_{p q}$ is the mass transfer from phase $\mathrm{q}$ to phase $\mathrm{p}$ and $\dot{m}_{q p}$ is the mass transfer from phase $\mathrm{p}$ to phase q. Besides, $S_{\alpha_{q}}$ is the source term whose initial value is zero. The volume fraction equation can be solved either implicitly or explicitly. However, for higher accuracy, the implicit method was used in this study. When using the implicit method, the volume fraction equation is discretized into algebraic functions as follows. 


$$
\begin{aligned}
\frac{\alpha_{q}^{n+1} \rho_{q}^{n+1}-\alpha_{q}^{n} \rho_{q}^{n}}{\Delta t} & V \\
& +\sum_{f}\left(\rho_{q}^{n+1} U_{f}^{n+1} \alpha_{q, f}^{n+1}\right) \\
& =\left[S_{\alpha_{q}} \sum_{p=1}^{n}\left(\dot{\mathrm{m}}_{p q}-\dot{\mathrm{m}}_{q p}\right)\right] \mid
\end{aligned}
$$

Where: $\mathrm{n}+1$ is the time step number being calculated, $\mathrm{n}$ is the previous time step number, $\alpha_{q}^{n+1}$ is the volume fraction in the cell in the current step, $\alpha_{q}^{n}$ is the volume fraction in the cell in the previous step, $\alpha_{q, f}^{n+1} 1$ is the surface value of the volume fraction in the current step, $U_{q, f}^{n+1}$ is the volume flux value of the surface in the current step, and $\mathrm{V}$ is the cell volume.

$$
\begin{aligned}
\frac{\partial}{\partial t}(\rho \vec{v})+\nabla \cdot(\rho \vec{v} \vec{v}) & =-\nabla p+\nabla \cdot\left[\mu\left(\nabla \vec{v}+\nabla \vec{v}^{T}\right)\right. \\
& +\rho \vec{g}+\vec{F}
\end{aligned}
$$

Since the desired results are at high depths, the turbulence effects are very small and the K- $\varepsilon$ model will be used for this solution.

The K-Epsilon turbulence model is a two-equation model that solves the transport equations for the turbulent kinetic energy and its dissipation rate to determine the turbulent viscosity.

Homogeneous fluid motion equations without chemical reaction and mass propagation are based on three laws of conservation. In this study, the differential equations of fluid motion stability are:

$\frac{d \rho}{d t}+\nabla \cdot(\rho V)=0$

Equation (4) is the continuum equation and Equation (5-7) is the momentum equation form. The equations 5, 6, and 7 are related to the $X, Y$ and $\mathrm{Z}$ components, respectively.

$\rho \frac{D u}{D t}=-\frac{\partial p}{\partial x}+\frac{\partial \tau_{x x}}{\partial x}+\frac{\partial \tau_{y x}}{\partial y}+\frac{\partial \tau_{z x}}{\partial z}+\rho f_{x}$

$\rho \frac{D u}{D t}=-\frac{\partial \rho}{\partial y}+\frac{\partial \tau_{x y}}{\partial x}+\frac{\partial \tau_{y y}}{\partial y}+\frac{\partial \tau_{z y}}{\partial z}+\rho f_{y}$

$\rho \frac{D u}{D t}=-\frac{\partial \rho}{\partial z}+\frac{\partial \tau_{x z}}{\partial x}+\frac{\partial \tau_{y z}}{\partial y}+\frac{\partial \tau_{z z}}{\partial z}+\rho f_{z}$

\section{SHIP GEOMETRY AND CONDITIONS}

Since the commercial oil tankers have a significant share of freight in the seas and generally travel in shallow bays, the applied geometry is a model of a relatively real-sized oil tanker, as shown in Fig. 1.

These tankers generally have a bubble nose in the bow to reduce the wave-making phenomenon and reduce the drag force. Since the focus of this research is to investigate the overall effects of the body on the velocity and water pressure field in the distant field of the ship, the partial appendix modeling has been neglected and analyzing only the main body model. The modified geometric model is in Fig. 2.
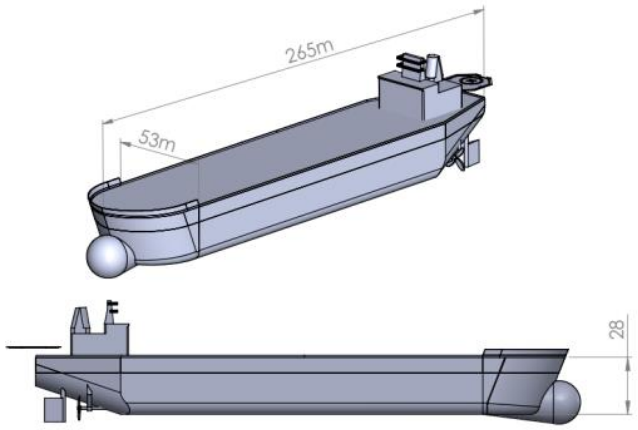

Fig. 1. Schematic view of the oil tanker used in the numerical analysis.

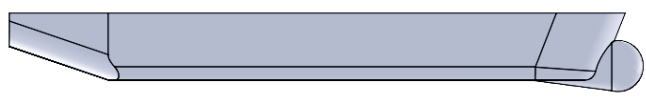

Fig. 2. Ship geometry model for the numerical analysis.

\subsection{Computation Domain and Boundary Conditons}

To design the computational domain dimensions, we used the computational domain dimensions in heavy vessels (Tezdogan et al. 2015; Begovic et al. 2015; De Luca et al. 2016) such as Fig. 3. However, in this case, the distance between the vessel's bottom and the bottom of the computational domain should be considered $80 \mathrm{~m}$. Boundary conditions are also shown in Fig. 4.

\section{Solution Method}

The numerical analysis was performed as the base pressure and in an unstable state. To investigate hydrostatic pressures, the multi-phase VOF model with open channel settings, implicit body force, Boussinesq air, and water density definition and depth selection under boundary conditions associated with the Open Channel model with gravity effects were used.

To simulate the dynamic motion of the ship on a fixed seabed and extract the pressure field and velocities around the vessel body, and in particular, their effects on the floor, the slider grid, and the field division into two fixed and moving parts are used. Linear periodic boundary condition is defined for the front and back boundaries. The SIMPLEC schema is used to couple the pressure and velocity equations. The upstream quadratic method is devised to discretize the equations.

The settings use the time-dependent dynamic motion. The ground level is constant and the volume around the ship is moving at a linear velocity. The volume movement around the body is 

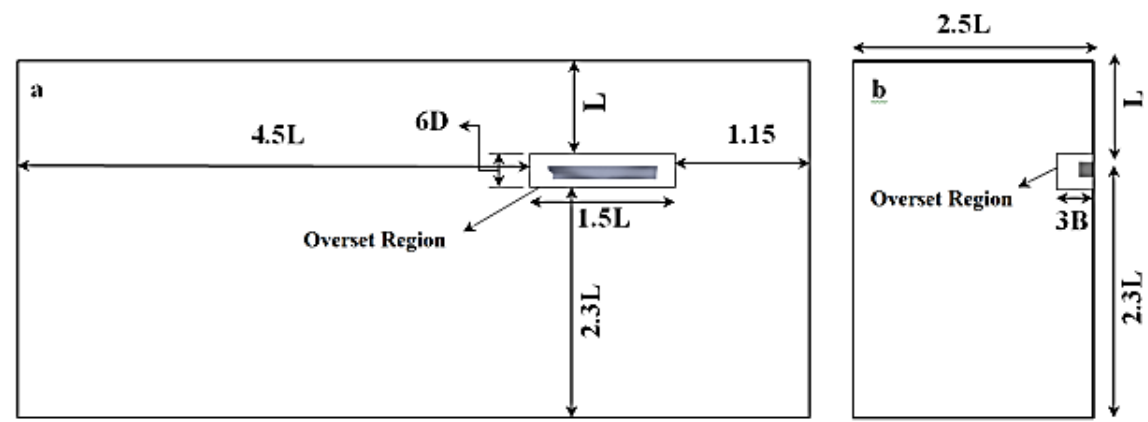

Fig. 3. Dimensions of the computational domain (a) Front view, (b) Side view, L: Length between perpendicular bow and foot, D: Ship draft, B: Half of the ship width.

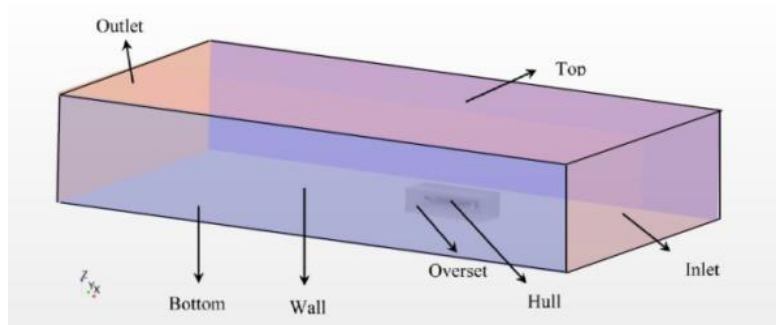

Fig. 4. Boundary conditions used in numerical solution.

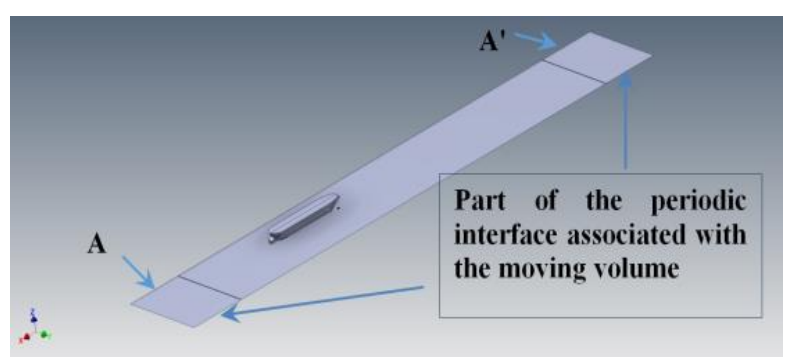

Fig. 5. Interfaces used in time - dependent dynamic motion.

repetitive, that is despite the grid's limited volume, and the conditions create an infinite state. Periodic interface boundary condition is used to correlate the fixed surface areas of moving and stationary volumes so that they are maintained in different one-to-one communication conditions. The mentioned interfaces are shown in the following figure.

Despite the surfaces movement on each other and taking distance from one another, the fluid points are interconnected one by one. For example, point A grid is connected to point $\mathrm{A}^{\prime}$ grid from another interface and the connection between the surfaces never interrupts anywhere.

\subsection{Grid Study}

Due to the higher importance of compressive forces around the ship than viscous forces, an appropriate grid has been used to investigate the effect of the grid on the results of the grid independence. The solution conditions for the independence of the results from the grid, computational domain, and time step are as follows.

Velocity $=20$ knots

Depth of seafloor $=80 \mathrm{~m}$

The computational grid is created by a combination of structure and unstructured mesh (near the body). To create a suitable grid for numerical solution, the created grid is investigated in terms of the variation in cell size dependence. To investigate the grid independence, we studied the pressure and velocity field variations over several lines generated by the intersection of the middle plane and the multiple parallel planes of the middle plane at different widths with the free surface parallel planes at several different depths. The intersection lines start from 25 meters ahead of the ship and continue up to 50 meters after the ship.

Also, the height and transverse distance of the body of the ship are shown in the figures.

The location of the lines used in the grid independence study is shown in Table 1. 
Figure 7 shows the velocity diagram on the LX3 line and the velocity and pressure diagrams for the rest of the lines are neglected for brevity.

By examining the amount of pressure and velocity along the above lines, it was found that the pressure and velocity fields around the ship change slightly as the grid grows. Accordingly, changes in the 1200,000 grid cells and above are negligible and in the 20,000,000 grid cells, independence grid can be achieved.

'?

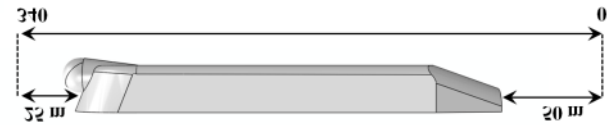

Fig. 6. Line spacing and the coordinate center in the grid independence report.

Table 1 Location of lines used in the grid independence

\begin{tabular}{|c|c|c|}
\multicolumn{3}{|c}{ independence } \\
\hline $\begin{array}{c}\text { Lines } \\
\text { name }\end{array}$ & $\mathrm{Y}(\mathrm{m})$ & $\mathrm{Z}(\mathrm{m})$ \\
\hline LX1 & 0 & $\begin{array}{c}-25(-8 \mathrm{~m} \text { beneath } \\
\text { the ship) }\end{array}$ \\
\hline LX2 & -25 & $\begin{array}{c}-25(-8 \mathrm{~m} \text { beneath } \\
\text { the ship })\end{array}$ \\
\hline LX3 & $\begin{array}{c}-30(-5 \mathrm{~m} \text { from the } \\
\text { side of the ship) }\end{array}$ & -10 \\
\hline LX4 & $\begin{array}{c}-35(-10 \mathrm{~m} \text { from the } \\
\text { side of the ship) }\end{array}$ & -10 \\
\hline
\end{tabular}

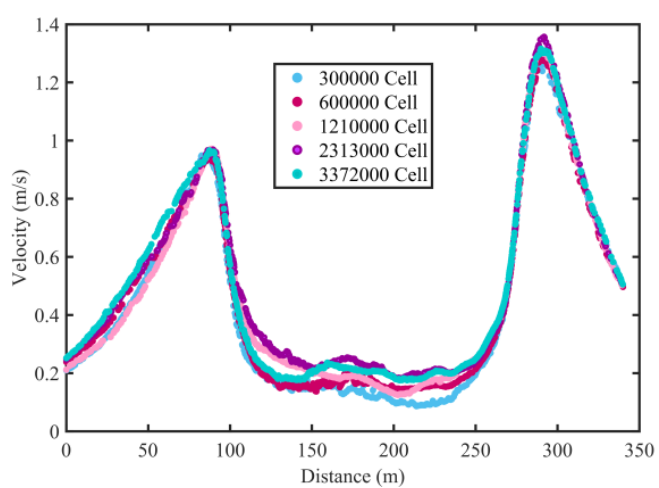

Fig. 7. Grid independence study on the LX3 line.

Figures 8 to 10 illustrate the gridding in different directions and planes.

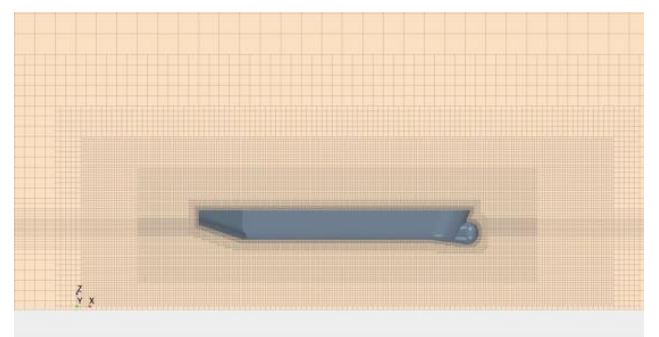

Fig. 8. Grid's side view.

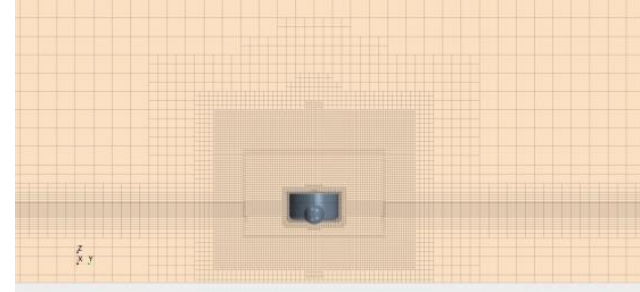

Fig. 9. Grid's front view.

To investigate the grid independence, the drag force variations are calculated in terms of the number of computational cells and shown in Fig. 11. However, since the purpose of this study is to analyze the current around the ship, the grid independence is only discussed based on the current around the ship.

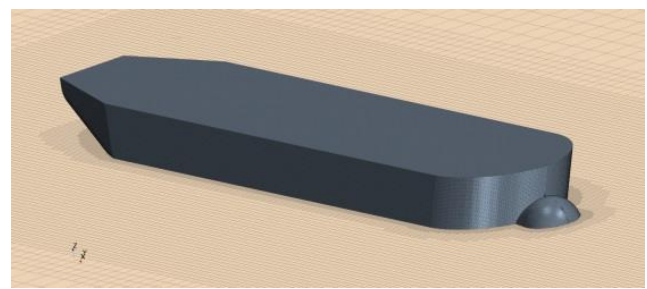

Fig. 10. Gridding the body and draft plane

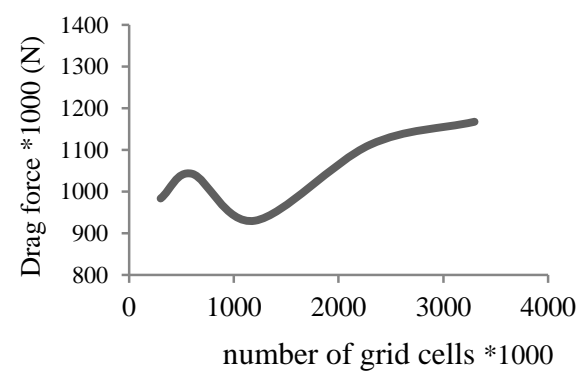

Fig. 11. Convergence of drag versus number of grid cells.

The time step used in this simulation is a function of body velocity and based on the ITTC equation (ITTC, 2011):

$\Delta t=0.01 \sim 0.005 \frac{l}{V}$

Where, $V$ is the velocity of the body and $l$ is the characteristic value of the analyzed body.

\section{VALIDATION}

To validate the numerical solution results, the KCS ship model (Fig.12) reported by W.J. Kim et al. (2001) has been solved numerically. Table 2 provides the model information. Figs. 13 to 15 show the changes in the velocity field relative to the kcs velocity. Moreover, $\mathrm{X}, \mathrm{Y}$ and $\mathrm{Z}$ coordinates are dimensionless concerning the length of the vessel and the center of the coordinates is in the middle of the vessel on the free surface of the water. 


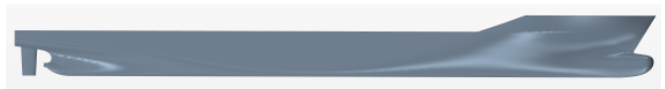

Fig. 12. Side view of the kcs hull.

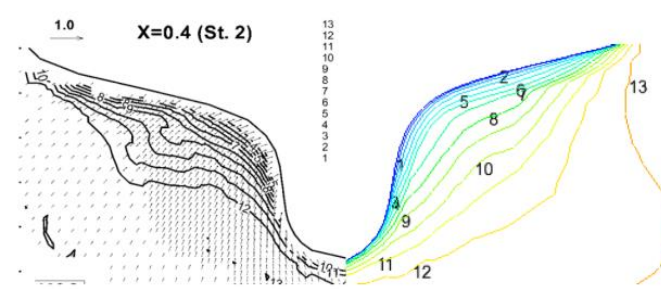

Fig. 13. Measured mean velocity fields around KCS. at $X=0.4$ [left] and present results [right].

Table 2 The specifications of the model used in the work performed by Kim et al. (2001)

\begin{tabular}{|c|c|}
\hline Designation & TT model \\
\hline Speed $(\mathrm{m} / \mathrm{s})$ & 2.1964 \\
\hline Froude number $(\mathrm{Fr})$ & 0.26 \\
\hline Reynolds number $(\mathrm{Re})$ & $1.4 \times 10^{7}$ \\
\hline Length $(\mathrm{m})$ & 7.2786 \\
\hline Breadth $(\mathrm{m})$ & 1.0190 \\
\hline Depth $(\mathrm{m})$ & 0.6013 \\
\hline Draft $(\mathrm{m})$ & 0.3418 \\
\hline Wetted surface area $\left(\mathrm{m}^{2}\right)$ & 9.5121 \\
\hline
\end{tabular}

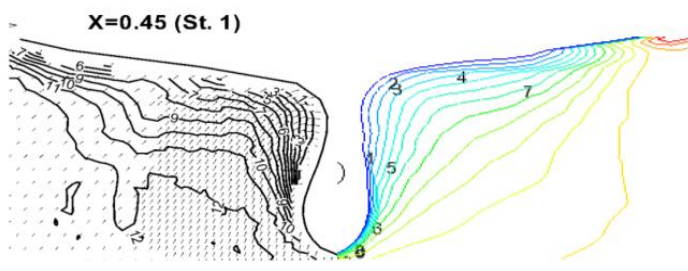

Fig. 14. Measured mean velocity fields around KCS. at $\mathrm{X}=0.45$ [left] and present results [right].

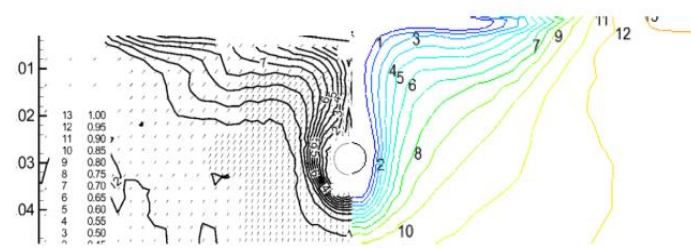

Fig. 15. Measured mean velocity fields around KCS. at $X=0.4825$ [left] and present results [right].

Both numerical and experimental velocity are compared at $\mathrm{x}=0.4$ on the line $\mathrm{Y}=-0.02$ (Fig. 16) and at $\mathrm{x}=0.4825$ on the line $\mathrm{z}=-0.01$ (Fig. 17). These results are presented in Table 111 and Table 222 , Where the error rate in the first case is about $4.81 \%$ and in the second case is $4.68 \%$. As a result, the mean error in both situations is less than $5 \%$.

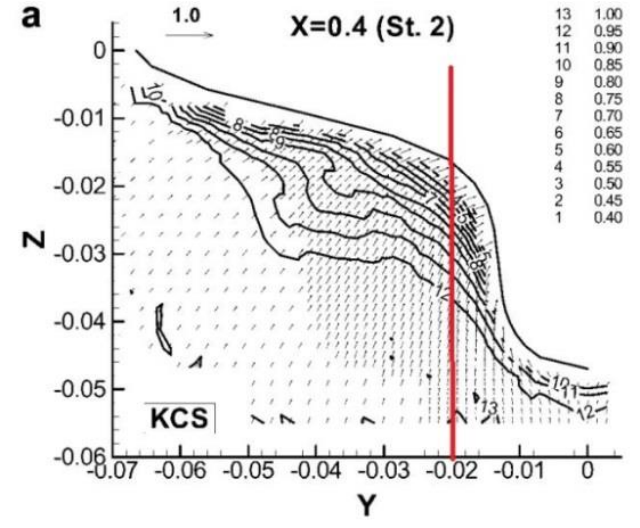

Fig. 16. Select line $Y=-0.02$ at $x=0.4$.

Table 3 Comparison of the velocity obtained in this study with the work performed by Kim et al. (2001) at $\mathrm{X}=0.4, \mathrm{Y}=\mathbf{- 0 . 0 2}$

\begin{tabular}{|c|c|c|c|}
\hline $\mathrm{X}=0.4$ & \multicolumn{2}{|c}{$\begin{array}{c}\text { Dimensionless } \\
\text { velocity }\end{array}$} & \\
\hline $\mathrm{Z}$ & $\begin{array}{c}\text { Experiment } \\
\text { al results }\end{array}$ & $\begin{array}{c}\text { present } \\
\text { results }\end{array}$ & Error $\%$ \\
\hline-0.02071 & 0.45 & 0.4789 & 6.432869 \\
\hline-0.02156 & 0.5 & 0.5525 & 10.51763 \\
\hline-0.02284 & 0.55 & 0.5946 & 8.117142 \\
\hline-0.02383 & 0.6 & 0.6351 & 5.865399 \\
\hline-0.02496 & 0.65 & 0.6974 & 7.30248 \\
\hline-0.02539 & 0.7 & 0.751 & 7.289881 \\
\hline-0.02624 & 0.75 & 0.7697 & 2.631866 \\
\hline-0.02794 & 0.8 & 0.7961 & 0.478717 \\
\hline-0.03064 & 0.85 & 0.8372 & 1.502131 \\
\hline-0.03319 & 0.9 & 0.8739 & 2.89024 \\
\hline-0.03702 & 0.95 & 0.9246 & 2.672574 \\
\hline-0.04043 & 1 & 0.9792 & 2.077019 \\
\hline & & & $\begin{array}{c}\text { Mean= } \\
\end{array}$ \\
\hline
\end{tabular}

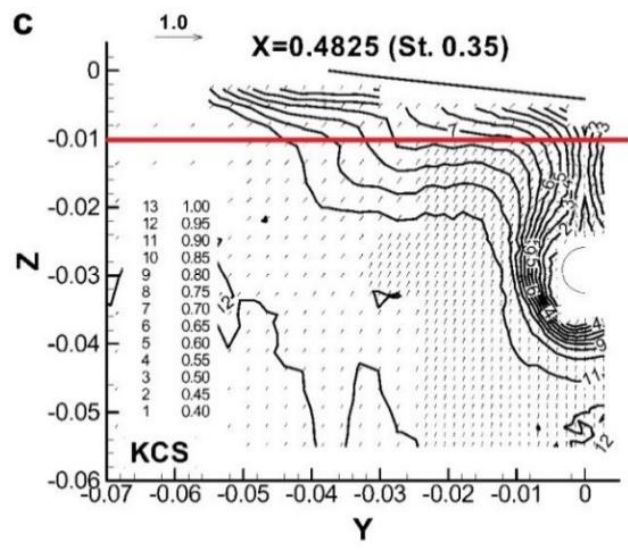

Fig. 17. Select line $Z=\mathbf{- 0 . 0 1}$ at $x=0.482$.

Figure 18 shows the free surface deformation around the KCS hull. In addition, in Figure 19. 


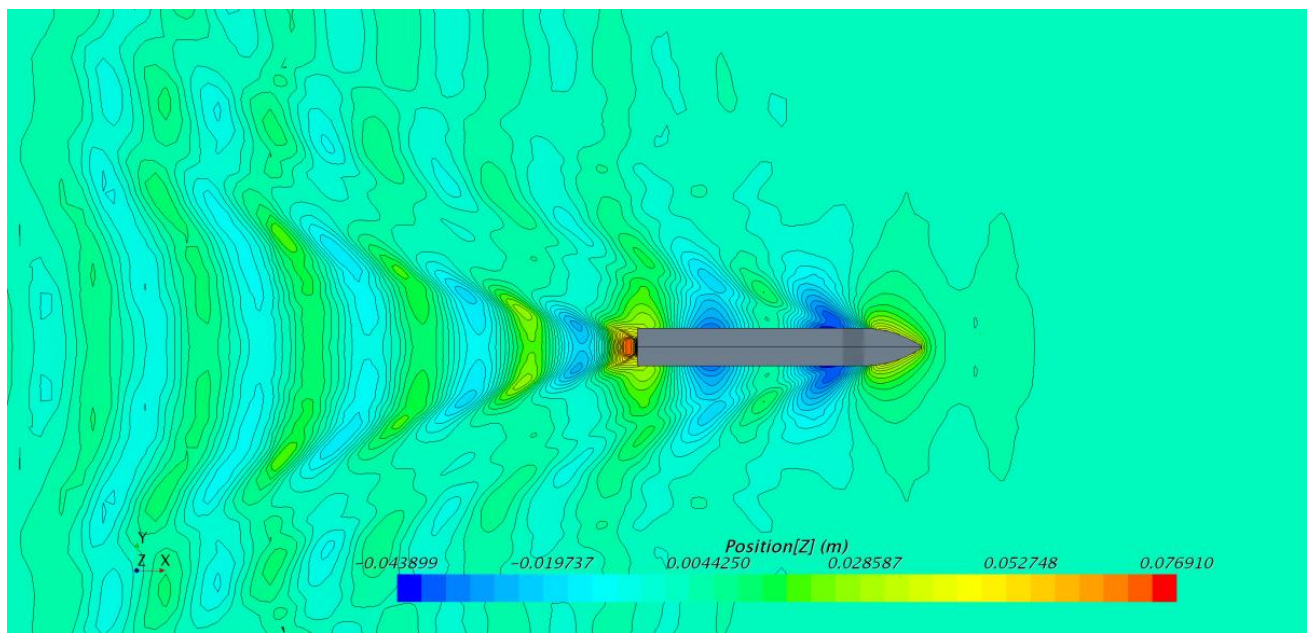

Fig. 18. Free surface deformation around the KCS hull.

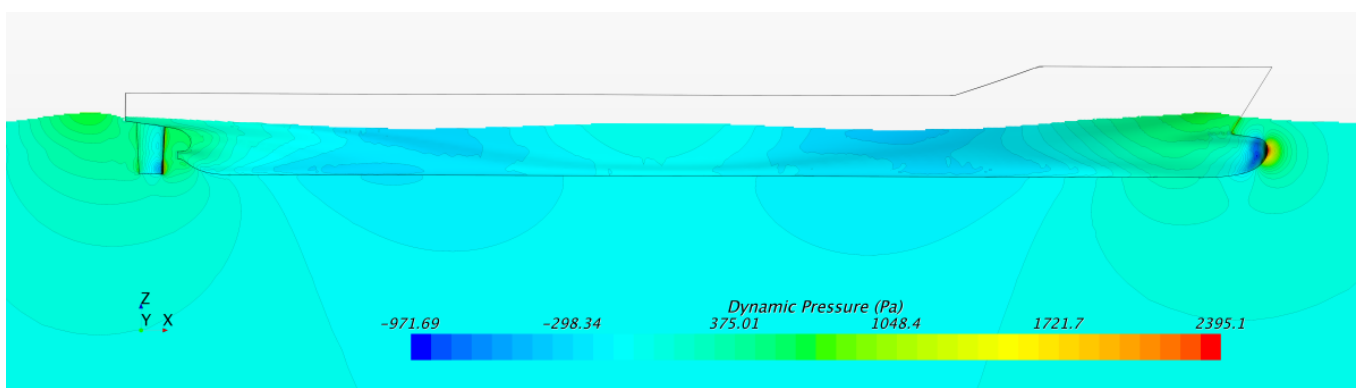

Fig. 19. Hydrodynamic pressure on the KCS hull and around the KCS hull below the free surface of water.

Table 4 Comparison of the velocity obtained in this study with the work performed by Kim et al. (2001) at $\mathrm{X}=\mathbf{0 . 4 8 2 5 ,} \mathrm{Z}=\mathbf{- 0 . 0 1}$

\begin{tabular}{|c|c|c|c|}
\hline $\mathrm{X}=0.4825$ & $\begin{array}{c}\text { Dimensionless } \\
\text { velocity }\end{array}$ & \\
\hline $\mathrm{Y}$ & $\begin{array}{c}\text { Experime } \\
\text { ntal results }\end{array}$ & $\begin{array}{c}\text { present } \\
\text { results }\end{array}$ & Error \% \\
\hline-0.00059 & 0.45 & $4.58 \mathrm{E}-01$ & 1.810189 \\
\hline-0.00187 & 0.5 & $4.92 \mathrm{E}-01$ & 1.607467 \\
\hline-0.00287 & 0.55 & $5.29 \mathrm{E}-01$ & 3.851841 \\
\hline-0.00429 & 0.6 & $5.69 \mathrm{E}-01$ & 5.238187 \\
\hline-0.00643 & 0.65 & $6.02 \mathrm{E}-01$ & 7.433336 \\
\hline-0.00998 & 0.7 & $6.77 \mathrm{E}-01$ & 3.30333 \\
\hline-0.02734 & 0.75 & $7.16 \mathrm{E}-01$ & 4.483983 \\
\hline-0.03232 & 0.8 & $7.50 \mathrm{E}-01$ & 6.188887 \\
\hline-0.0373 & 0.85 & $8.08 \mathrm{E}-01$ & 4.886706 \\
\hline-0.0447 & 0.9 & $9.72 \mathrm{E}-01$ & 7.957783 \\
\hline & & & Mean $=4.676171$ \\
\hline
\end{tabular}

shows the hydrodynamic pressure created on and around the KCS hull, at below the free surface of water. The drag force is also $38.9 \mathrm{~N}$.

\section{Presentation And Analysis Of RESULTS}

In the present study, using the numerical analysis of the flow field, the rate of hydrodynamic pressure depreciation caused by the vessel's movement at 80 $\mathrm{m}$ depth is obtained at 10,15 and 20 knots at various distances from the free surface of the water to the sea floor $(80 \mathrm{~m}$ depth). In this work, to eliminate the pressure changes due to the depth, the hydrodynamic pressure is considered as the pressure value minus the hydrostatic pressure for the relevant depths.

Figure 20 shows the hydrodynamic pressure contours in parallel planes to free surface of sea at 20 knots with various depths. This behavior is theoretically justified by the Bernoulli equation. The pressure increases in front of the ship due to the water being split by the ship and the fluid motion.

In the middle of the ship, the pressure decreases as the velocity increases. The behavior in the rear part of the ship is a little more complicated. As the current enters the static marine environment, the velocity decreases abruptly resulting in increased pressure.

The maximum hydrodynamic pressure at different 
Hydrodynamic Pressure field
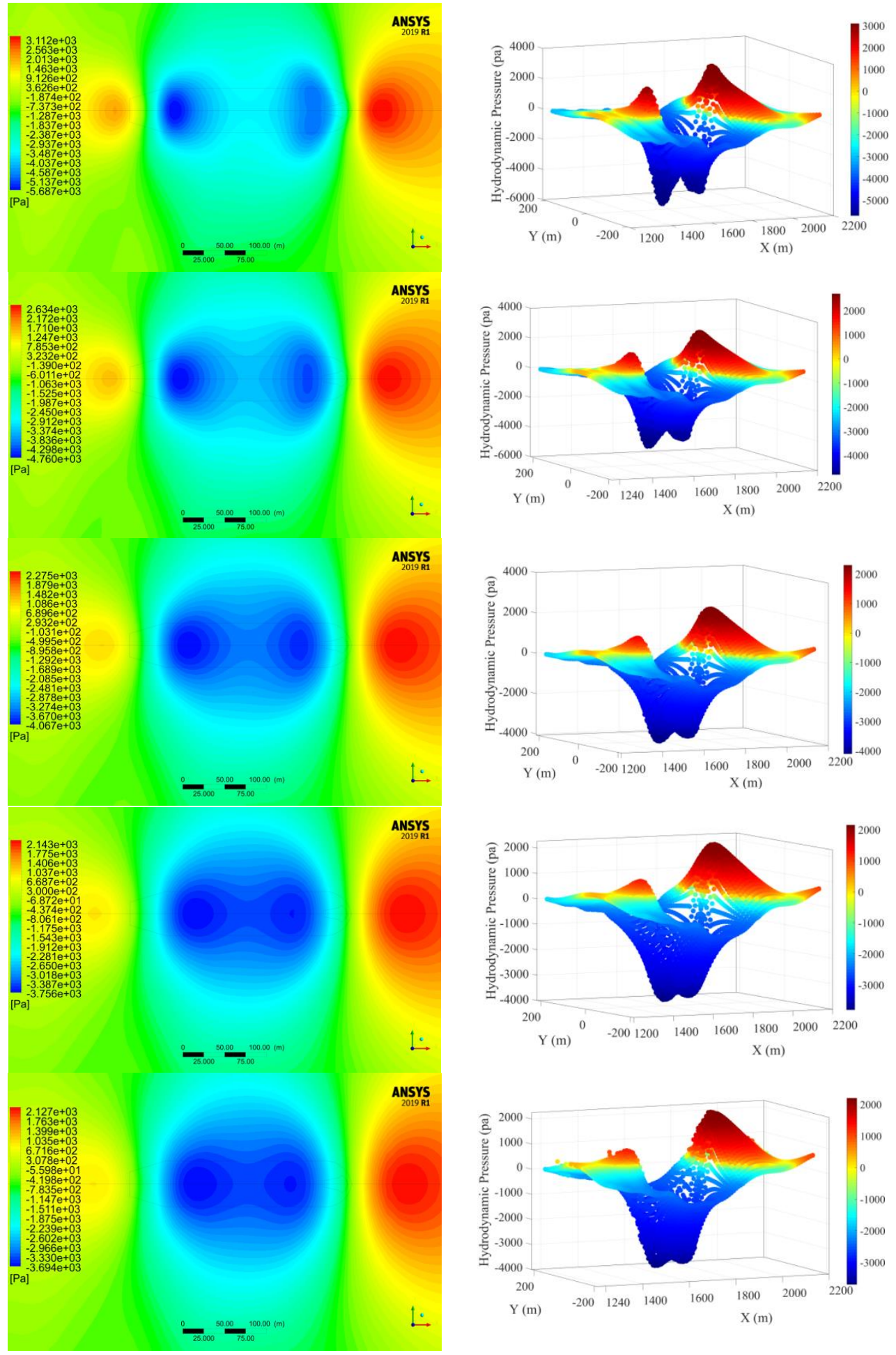

Fig. 20. Hydrodynamic pressure contours created by the vessel at 20 knots with different depths.

depths below the vessel is shown as negative pressure. Figure 21 shows the graph of the maximum negative pressure created at different velocities. As can be seen, if the velocity increases, the hydrodynamic pressure decreases with higher slope.

Figure 22 presents the normalized hydrodynamic 


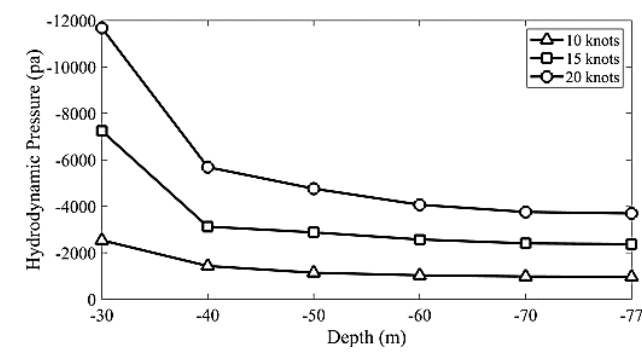

Fig. 21. Changes in the maximum hydrodynamic pressure created by the movement of the ship at different velocities and depths.

pressure $\left(\frac{P_{H}}{1 / 2^{*} \rho * V^{2}}\right)$ and the rate of hydrodynamic pressure reduction. The results show that at closer distances to the bottom of the vessel, the rate of pressure drop is faster and decreases with moving away. As shown in Fig. 22, the hydrodynamic pressure $\left(\mathrm{P}_{\mathrm{H}}\right)$ decrease with increasing depth at all velocities is slightly different so that the average percentage decrease in $\mathrm{P}_{\mathrm{H}}$ with increasing depth at 10 knots is $27.04 \%, 26.42 \%$ at 15 knots and $27.95 \%$ at 20 knots. Table 4 shows the figures for the percentage of decrease in $\mathrm{P}_{\mathrm{H}}$. If the $\mathrm{P}_{\mathrm{H}}$ value at 10 $\mathrm{m}$ depth is $\mathrm{p} 1$ and $\mathrm{p} 2$ at $20 \mathrm{~m}$ depth, the percentage of decrease in $\mathrm{P}_{\mathrm{H}}$ (normalized hydrodynamic pressure) at $20 \mathrm{~m}$ of depth is: $D P=\frac{\left|p_{1}-p_{2}\right| \times 100}{p_{1}}$

Table 5 Normalized hydrodynamic pressure at different speeds and depths

\begin{tabular}{|c|c|c|c|}
\hline \multirow{2}{*}{$\begin{array}{c}\text { Depth } \\
(\mathrm{m})\end{array}$} & \multicolumn{3}{|c|}{ Normalized hydrodynamic pressure } \\
\cline { 2 - 4 } & 10 knots & 15 knots & 20 knots \\
\hline-30 & 81.73 & 75.21 & 76.26 \\
\hline-40 & 43.7 & 56.85 & 51.31 \\
\hline-50 & 20.28 & 7.93 & 16.3 \\
\hline-60 & 9.65 & 10.67 & 14.56 \\
\hline-70 & 4.85 & 6.42 & 7.65 \\
\hline-77 & 2.04 & 1.45 & 1.65 \\
\hline Mean & 27.04 & 26.42 & 27.95 \\
\hline
\end{tabular}

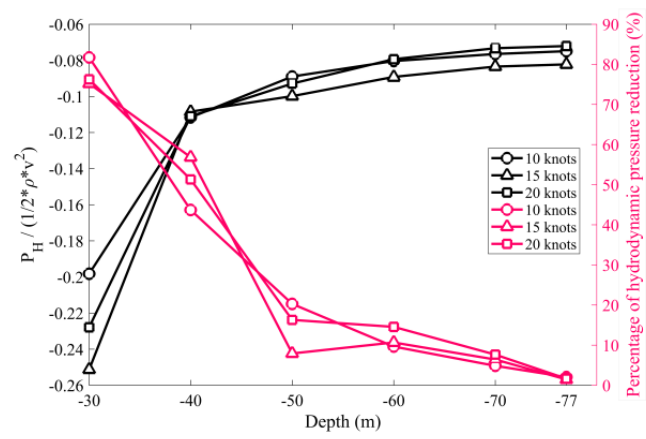

Fig. 22. Normalized hydrodynamic pressure at different depths and velocities.
Since the hydrodynamic pressure is directly related to the second power of velocity, the hydrodynamic pressure equation is written in terms of velocity and depth as $a+b * y^{2} * x^{c} \quad$ (Fig. 23) with its coefficients extracted by MATLAB Cftools.

$198.8+3610 * \mathrm{y}^{2} * \mathrm{x}^{-1.458}$

Goodness of fit: SSE: $2.489 \mathrm{e}+06$, R-square: 0.9733, Adjusted R-square: 0.9689.

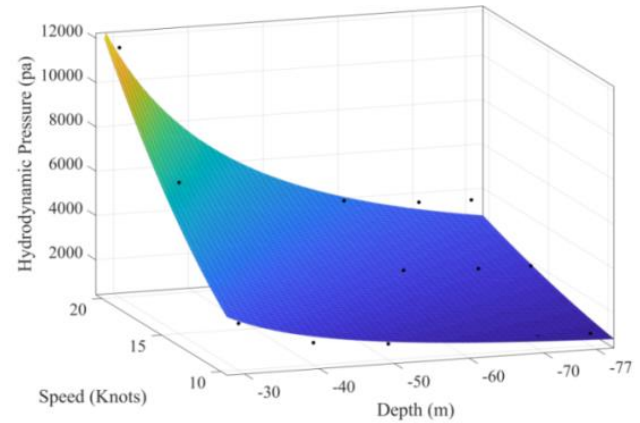

Fig. 23. Extraction of hydrodynamic pressure equation in terms of velocity and depth.

Figure 25 shows the changes in free surface of water at $12 \mathrm{~m}$ draft and different speeds.

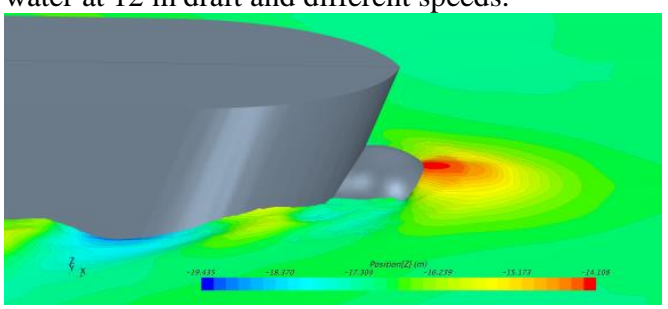

Fig. 24. free surface deformation around the hull at 20 knots with $12 \mathrm{~m}$ of draft.

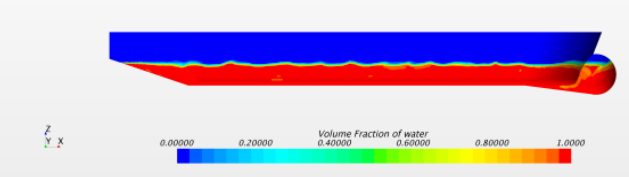

(a) Speed: 10 knots

(b) Speed: 15 knots

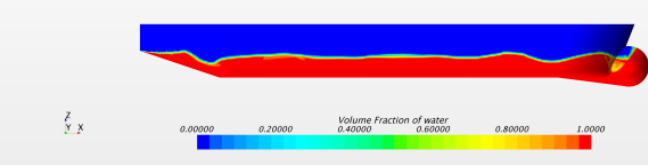

(c) Speed: 20 knots

Fig. 25. Free surface representation on the ship hull. 
Figure 26 shows the relationship between the drag force and the Froude number.

In Fig. 27 shows the bulbous bow drowning with different drafts. In Fig. 28 the amount of hydrodynamic pressure was compared on the middle plane at 20 knots and $70 \mathrm{~m}$ of depth with different drafts. The amount of negative pressure with $7 \mathrm{~m}$ of draft differs greatly from that of $12 \mathrm{~m}$ and $17 \mathrm{~m}$ drafts, which is predicted due to the difference in the amount of bulbous bow immersion in the water.

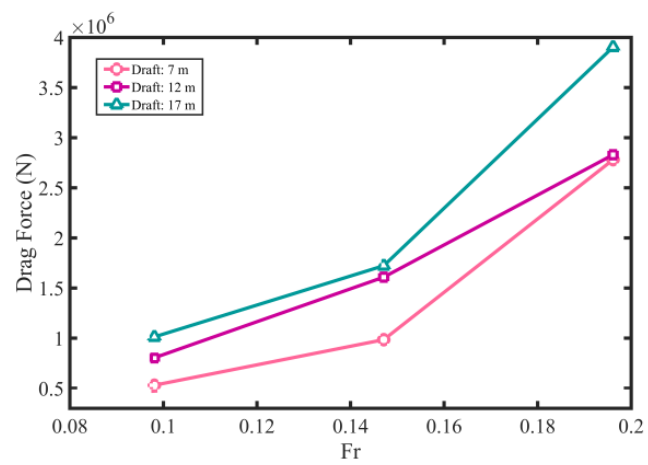

Fig. 26. Variation of drag force with Froude number.

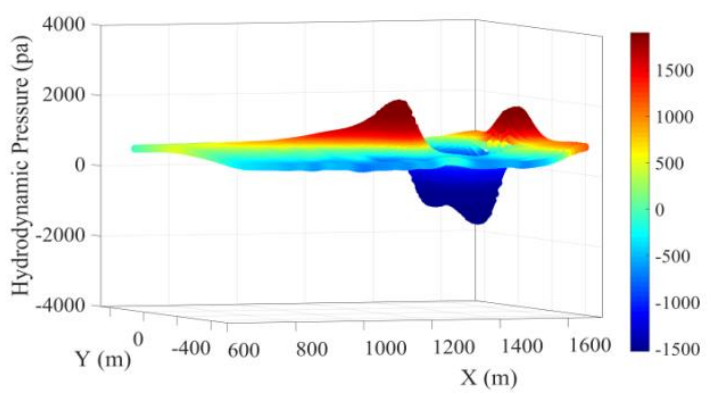

(a) Depth: $60 \mathrm{~m}$, Draft: $7 \mathrm{~m}$

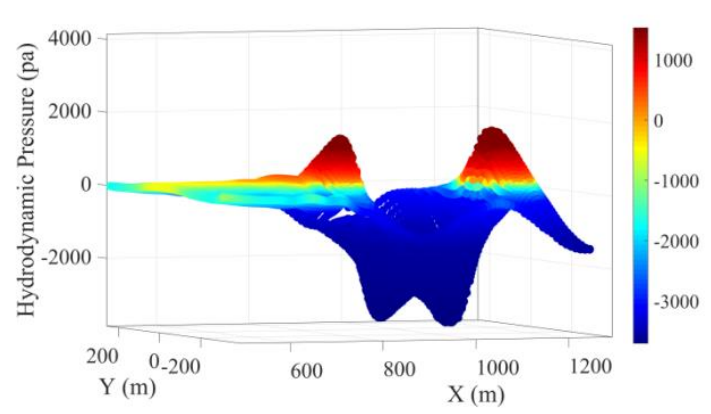

(b) Depth: 60 m , Draft: $12 \mathrm{~m}$

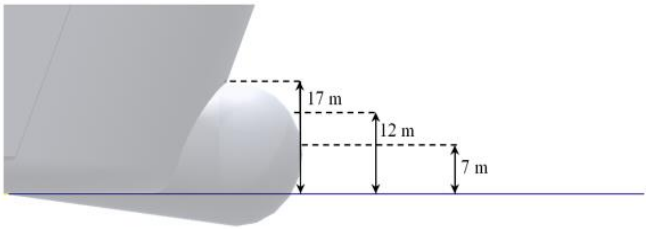

Fig. 27. Bulbous bow immersion in water with different drafts.

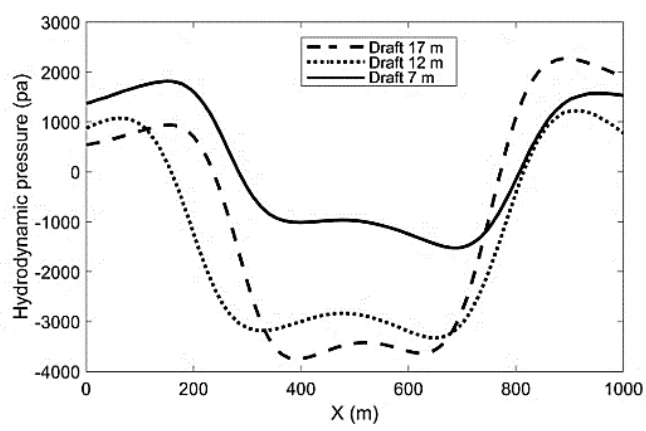

Fig. 28. Hydrodynamic pressure on the middle plane at 20 knots and $70 \mathrm{~m}$ of depth with different drafts.

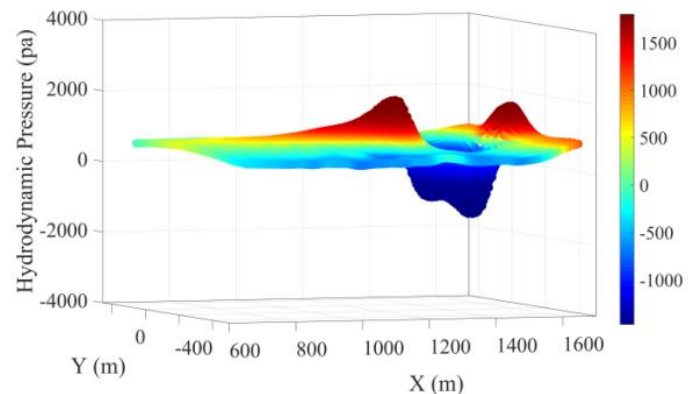

(d) Depth: 77 m , Draft: $7 \mathrm{~m}$

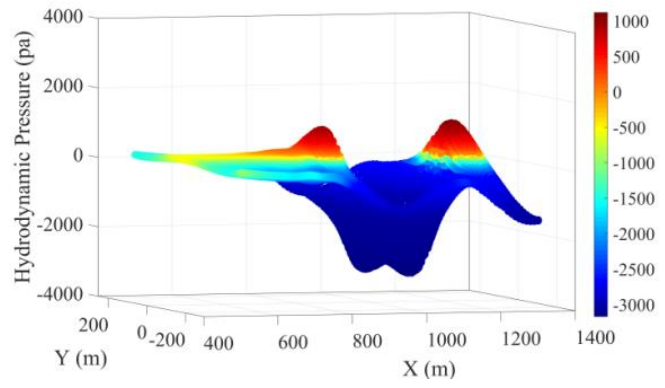

(e) Depth: $77 \mathrm{~m}$, Draft: $12 \mathrm{~m}$ 


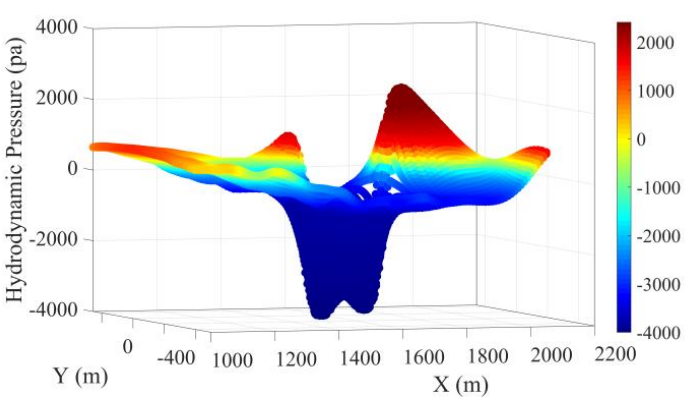

(c) Depth: $60 \mathrm{~m}$, Draft: $17 \mathrm{~m}$

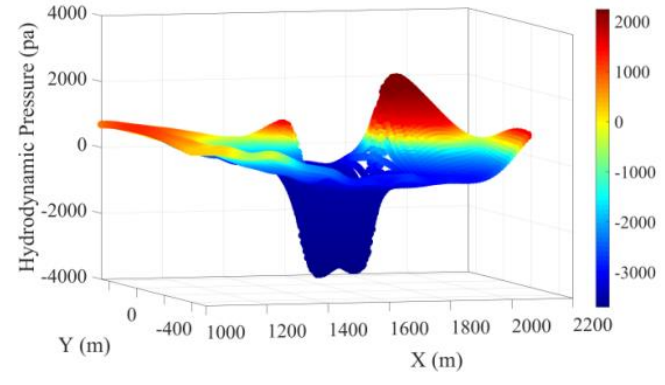

(f) Depth: 77 m, Draft: $17 \mathrm{~m}$

Fig. 29. Comparison of hydrodynamic pressure at 20 knots with different drafts.
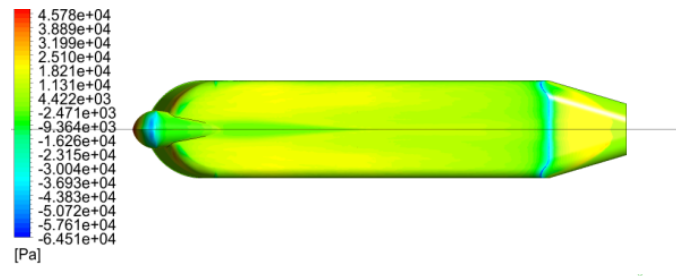

(a) Draft: $7 \mathrm{~m}$

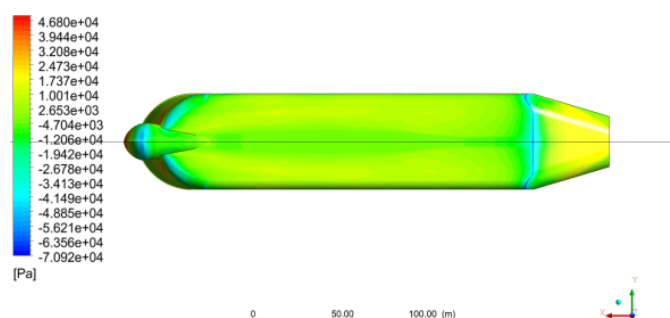

(b) Draft: $12 \mathrm{~m}$

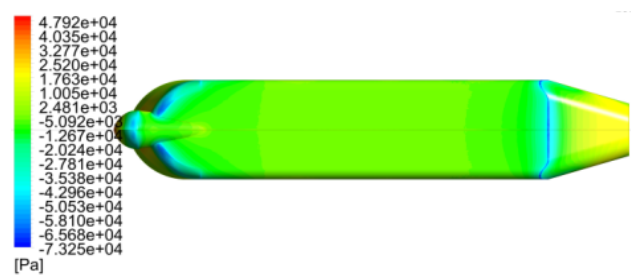

(c) Draft: $17 \mathrm{~m}$

Fig. 30. Pressure contour on the bottom of vessel at 20 knots.

\section{CONCLusion}

Numerical analysis of hydrodynamic pressure field due to an oil tanker motion has done for different sea depths up to $80 \mathrm{~m}$ and different speeds of 10,15 and 20 knots. The results showed by increasing the speed, the decaying rate of the relevant hydrodynamic pressure is faster than those related to lower speed; however, the effect of speed on the normalized hydrodynamic pressure is same for different depths. A new correlation for hydrodynamic pressure has been proposed in terms of the ship speed and the depth. The correlation shows the pressure varies with depth to a power of 1.45. With increasing the draft of vessel, the relevant hydrodynamic pressure also magnifies. The submergence of bulbous bow and the ship's bottom pressure are two main parameters that affect on the hydrodynamic pressure at other distances from the body. It can be seen that for more bulbous bow submergences of $\frac{3}{4}$ height, the increase of draft has little effect on the hydrodynamic pressure field.

\section{REFERENCES}

Begovic, E., C. Bertorello and S. Mancini (2015). Hydrodynamic performances of small size swath craft. Brodogradnja/Shipbuilding 66(4). $1-22$.

Bishop, C. T. and M. A. Donelan (1987). Measuring Waves with Pressure Transducers. Coastal Engineering 11, 309- 328.

Chen, X. N. and S. D. Sharma (1995). A slender ship moving at a near-critical speed in a shallow channel. Journal of Fluid Mechanics 291(-1), 263.

Dand, I. W. (1977). The Physical Causes of Interaction and its Effects. Nautical Institute, Conference on Ship Handling.

De Luca, F., S. Mancini, S. Miranda and C. Pensa (2016). An extended verification andvalidation study of CFD simulations for planing hulls. Journal of Ship Research 60 (2), 101-118.

Deng, H., Z. H. Zhang, J. B. Liu, and Ch. Wang (2017). Research on hydrodynamic pressure field causing by ship moving in mixed flow. Ocean Engineering 136, 314-321. 
A. Nasseroleslami et al. / JAFM, Vol. 13, No. 5, pp. 1575-1586, 2020.

Deng, H., Z. Zhang, J. Gu and J. Liu (2014). Numerical calculation and analysis of nonlinear pressure field induced by ship motion at subcritical speed in shallow water. Ship Building of China 55(1), 11-18.

Gourlay, T. P. (2000). Mathematical and computational techniques for predicting the squat of ships. Ph. D. thesis, the University of Adelaide, Australia.

ITTC (2011). Recommended Procedures and Guidelines Practical Guidelines for ShipCFD Applications 7.5-03-02-03.

Kim, W., S. Van and D. Kim (2001). Measurement of flows around modern commercial ship models. Experiments in Fluids 31(5), 567-578.

Lazauskas, L. (2007). The hydrodynamic resistance, wave wakes and bottom pressure signatures of a 5900t displacement air warfare destroyer. Int. rep. Department Appl. Mathematics. The University of Adelaide, Adelaide.

McArthur, P. J. (2011). New thinking in ship generated hydrodynamic fields: introducing concepts for predicting bank suction and rejection. 2nd International Conference on ship Manoeuvring in Shallow and Confined
Water: Ship to Ship Interaction, Trondheim, Norway, May 239-252.

Meng, Q. C., H. Deng, M. Y. Hu and Z. H. Zhang (2018). Analytical models of ship hydrodynamic pressure field with dispersive effect in super-supercritical mixed flow. Ocean Engineering 167, 95-101.

Sahin, I. and M. C. Hyman (2001). Simulation of three-dimensional finite-depth wave phenomenon for moving pressure distributions. Ocean engineering 28(12), 1621-1630.

Tezdogan, T., Y. K. Demirel, P. Kellett, M. Khorasanchi, A. Incecik and O. Turan (2015). Full-scale unsteady RANS CFD simulations of ship behavior and performance in head seas due to slow steaming. Ocean Engineering 97, 186-206.

Tuck, E. (1978). Hydrodynamic problems of ships in restricted waters. Annual Review of Fluid Mechanics 10(1), 33-46.

Zhang, Z. H. and J. N. Gu (2006). Research on wave and pressure field caused by ship moving at high speed in shallow water. Chuanbo Lixue, Journal of Ship Mechanics 10(2), 1522. 